\title{
Web-Based Intervention Using Behavioral Activation and Physical Activity for Adults With Depression (The eMotion Study): Pilot Randomized Controlled Trial
}

Jeffrey D Lambert ${ }^{1}, \mathrm{PhD}$; Colin J Greaves ${ }^{2}, \mathrm{PhD} ;$ Paul Farrand ${ }^{3}, \mathrm{PhD}$; Lisa Price ${ }^{4}, \mathrm{PhD} ;$ Anne M Haase $^{5}, \mathrm{PhD}$; Adrian H Taylor ${ }^{6}, \mathrm{PhD}$

\footnotetext{
${ }_{1}^{1}$ Institute for Health Research, Primary Care, University of Exeter Medical School, Exeter, United Kingdom

${ }^{2}$ School for Sport, Exercise and Rehabilitation, University of Birmingham, Birmingham, United Kingdom

${ }^{3}$ Clinical Education, Development and Research, Psychology, University of Exeter, Exeter, United Kingdom

${ }^{4}$ Sport and Health Sciences, University of Exeter, Exeter, United Kingdom

${ }^{5}$ Centre for Exercise, Nutrition and Health Sciences, University of Bristol, Bristol, United Kingdom

${ }^{6}$ Faculty of Medicine \& Dentistry, University of Plymouth, Plymouth, United Kingdom
}

\section{Corresponding Author:}

Jeffrey D Lambert, $\mathrm{PhD}$

Institute for Health Research

Primary Care

University of Exeter Medical School

Smeall Building

Heavitree Roadd, University of Exeter

Exeter, EX1 2LU

United Kingdom

Phone: 441392725705

Email: j.d.lambert@exeter.ac.uk

\section{Abstract}

Background: Physical activity is a potentially effective treatment for depression and depressive relapse. However, promoting physical activity in people with depression is challenging. Interventions informed by theory and evidence are therefore needed to support people with depression to become more physically active. eMotion is a Web-based intervention combining behavioral activation and physical activity promotion for people in the community with symptoms of depression.

Objective: The objectives were to assess the feasibility and acceptability of delivering eMotion to people in the community with symptoms of depression and to explore outcomes.

Methods: Participants with elevated depressive symptoms were recruited from the community through various methods (eg, social media) and randomized to eMotion or a waiting list control group for 8 weeks. eMotion is an administratively supported weekly modular program that helps people use key behavior change techniques (eg, graded tasks, action planning, and self-monitoring) to re-engage in routine, pleasurable, and necessary activities, with a focus on physical activities. Feasibility data were collected that included the following: recruitment and trial retention rates; fidelity of intervention delivery, receipt, and enactment; and acceptability of the intervention and data collection procedures. Data were collected for the primary (depression) and secondary outcomes (eg, anxiety, physical activity, fidelity, and client satisfaction) at baseline and 2 months postrandomization using self-reported Web-based questionnaires and accelerometers. Delivery fidelity (logins, modules accessed, time spent) was tracked using Web usage statistics. Exploratory analyses were conducted on the primary and secondary outcomes.

Results: Of the 183 people who contacted the research team, 62 were recruited and randomized. The mean baseline score was 14.6 (SD 3.2) on the 8-item Patient Health Questionnaire depression scale (PHQ-8). Of those randomized, 52 participants provided accelerometer-recorded physical activity data at baseline that showed a median of 35.8 (interquartile range [IQR] 0.0-98.6) minutes of moderate-to-vigorous physical activity (MVPA) recorded in at least 10-minute bouts per week, with only 13\% (7/52) people achieving guideline levels (150 minutes of MVPA per week). In total, 81\% (50/62) of participants provided follow-up data for the primary outcome (PHQ-8), but only 39\% (24/62) provided follow-up accelerometer data. Within the intervention group, the median number of logins, modules accessed, and total minutes spent on eMotion was 3 (IQR 2.0-8.0), 3 (IQR 2.0-5.0), 
and 41.3 (IQR 18.9-90.4), respectively. Acceptability was mixed. Exploratory data analysis showed that PHQ-8 levels were lower for the intervention group than for the control group at 2 months postrandomization (adjusted mean difference $-3.6,95 \%$ CI -6.1 to -1.1$)$.

Conclusions: It was feasible to deliver eMotion in UK communities to inactive populations. eMotion has the potential to be effective and is ready for testing in a full-scale trial. Further work is needed to improve engagement with both the intervention and data collection procedures.

Trial Registration: ClinicalTrials.gov NCT03084055; https://clinicaltrials.gov/ct2/show/NCT03084055 (Archived by WebCite at http://www.webcitation.org/6zoyM8UXa)

(J Med Internet Res 2018;20(7):e10112) doi: 10.2196/10112

\section{KEYWORDS}

psychological therapy; mood; anxiety; exercise; eHealth; feasibility; acceptability

\section{Introduction}

Depression has a significant detrimental impact on individuals and their families as well as being associated with increased utilization of health services and reduced productivity at work. In the UK, the cost to the economy due to sickness absence, staff turnover, benefits, fall in tax revenue, and costs to the National Health Service (NHS) is estimated to be between $£ 74$ billion and $£ 99$ billion per year [1]. Depression is also associated with a range of major physical illnesses (which are also associated with physical inactivity), including diabetes [2,3], coronary heart disease [4], and obesity [5].

Physical activity (PA) has been shown to be effective in treating [6-8] and preventing [9] depression and is often cited by patients as their preferred treatment option [10,11]. A recent systematic review of randomized controlled trials (RCTs) found PA to be more effective than control conditions for reducing depression (standardized mean difference [SMD] -0.62) and just as effective as pharmacotherapy (SMD -0.11) and psychological therapies (SMD -0.03) [6]. PA also has the potential to reduce depressive relapses [12], improve anxiety symptoms [13], and help prevent many physical health problems associated with depression such as cardiovascular disease, cancer, and diabetes [14]. Despite these benefits, PA is perceived as difficult to prescribe compared with medication [15]. Further studies are therefore needed to understand how and whether PA can be cost-effectively used to improve outcomes for people with depression, especially in those who are relatively inactive [16].

Behavioral activation (BA) is an evidenced-based psychological therapy. BA focuses on reducing an individual's exposure to sources of negative reinforcement (ie, short-term relief from avoiding burdensome activities) while increasing experiences of positive reinforcement (ie, social and personal activities that bring pleasure and achievement), leading to reduced avoidant type-behaviors in the future [17-19]. A meta-analysis of 26 RCTs ( $n=1524)$ conducted on adults with depression found BA to be superior to usual care, wait list, or placebo control conditions (SMD -0.74) and medication (SMD -0.42) for reducing depression [20]. The treatment rationale of BA shares behavior change techniques (BCTs) [21] with interventions promoting PA (eg, goal setting) [22]. By subtly shifting the behavioral emphasis, the treatment rationale of BA could therefore provide a useful delivery mechanism for promoting
PA in people with depression, capitalizing on the dual benefits of PA and BA. Furthermore, sustained PA may reduce the relapse rate associated with $\mathrm{BA}$ alone due to its inherent mood enhancing and long-term benefits [12].

Recent studies have examined the feasibility of delivering a combined BA and PA intervention (BAcPAc) within the context of existing mental health services [22,23]. However, BAcPAc was difficult to implement in overstretched services, it was hard to recruit patients, and problems of fidelity were observed, with providers not delivering the treatment as intended [23]. Web-based interventions could provide a useful way of overcoming these limitations by delivering such interventions outside of existing services, recruiting directly from the community, and standardizing fidelity [24,25]. Furthermore, Web-based interventions could have additional benefits by being scalable, cheap, and accessible [26]. Importantly, Web-based interventions can also be used to provide support to people experiencing depression in UK communities who do not seek help from health services due to social stigma and identity conflict [27]. However, despite the potential benefits associated with Web-based interventions, there remains a paucity of studies that have attempted to deliver Web-based interventions promoting PA for depression [28-31]. Furthermore, none of these studies have explored the feasibly of delivering a Web-based intervention combining BA and PA for people with depression.

The purpose of the present study was to examine the feasibility of delivering a Web-based intervention (eMotion), combining PA with BA, for people with depression and to explore its effects on depression and PA. The key aims of the study were to: explore participant recruitment and attrition rates throughout the study; explore the feasibility and acceptability of data collection and study procedures; examine baseline characteristics of the recruited sample, including levels of PA; explore the fidelity of delivery, receipt, and enactment (use of techniques) of eMotion and its acceptability to participants; and estimate and explore the variance in key outcomes (depression scores and PA). 


\section{Methods}

\section{Trial Design}

\section{Description of Trial Design}

The eMotion trial was a 2-arm, individually randomized, parallel-group pilot RCT with a nested process evaluation (ClinicalTrials.gov Identifier: NCT03084055). The study was reported in accordance with Consolidated Standards of Reporting Trials (CONSORT-EHEALTH) recommendations for reporting of RCTs of eHealth interventions [32] and the Template for Intervention Description and Replication (TIDieR) recommendations on reporting of behavior change interventions [33].

\section{Important Changes to Methods After Trial Commencement}

The eMotion trial provided "minimal contact" administrative support [34] at week 2 of the intervention to provide the participant with a rationale for the use of self-help materials and check-ins related to progress, but with no focus on any clinical or behavior change issues. This support was initially intended to be provided by an independent "supporter." However, due to resource issues, this support was provided by the lead author.

\section{Participants}

\section{Eligibility Criteria for Participants}

Participants were eligible for the study if they were more than 18 years old, were living in UK, had at least moderate depressive symptoms [defined as scoring at least 10 on the 8-item Patient Health Questionnaire depression scale (PHQ-8)], had access to the internet and were computer literate, reported being able to walk continuously and unaided for a minimum of $5 \mathrm{~min}$, and provided informed consent to participate. Eligible adults were recruited from the community via advertisements in weekly newspapers, social media (eg, Facebook support groups, Twitter), and through banners on websites relating to mental health problems. All adverts contained the primary investigator's contact details. Potential participants did not need to be referred by a general practitioner or mental health care practitioner. After contacting the lead author by phone or email, potential participants were sent the participant information sheet (PIS), consent form, and a link to the Web-based screening questionnaire via email. At this point, they were informed that they could withdraw from the study at any time without consequence or being obliged to provide a reason. Once participants read the PIS, they were asked to complete the Web-based consent form (indicating consent using a checkbox) followed by a screening questionnaire used by the lead author to assess participant eligibility. After screening, the lead author contacted the participant via phone to clarify the study procedures and provide instructions for wearing the wrist-worn accelerometers sent by post. The participant was instructed to wear the accelerometer for 7 days and return it in a pre-stamped addressed envelope. However, participant refusal to wear an accelerometer did not preclude randomization. Further baseline measures were then administered via a separate Web-based questionnaire. Participants were not paid for their involvement in the study.

\section{The eMotion Intervention}

The eMotion intervention is a Web-based course that provides people with access to an evidence-based treatment based on BA with added PA promotion. People with depression commonly reduce activities that they perceive as burdensome, making less effort to do things they may have previously enjoyed. By avoiding such activities, people with depression experience temporary relief that then negatively reinforces the likelihood of avoiding further activities. However, avoiding such activities has a long-term cost because it reduces the opportunities for positive reinforcement that occurs when people engage in social and personal activities that bring them pleasure and achievement [17-19]. PA is often avoided by people with depression, but it has the potential to provide additional anti-depressive benefits as well as added health benefits.

Through a series of steps delivered in a week-by-week modular fashion (Table 1), eMotion teaches people how to re-establish daily routines, increasing activities that provide positive reinforcement while reducing negative reinforcement. eMotion comprises 13 modules ( 1 introduction module, 8 weekly modules, 1 generic problem-solving module, and 3 unlockable modules) consisting of visual content with an audio voiceover triggered when each slide opens. Printable, interactive worksheets, and emails were also included, with links to the slides to allow downloading to a personal computer or another device (eg, tablet or smartphone). Automated reminder emails were also sent once a week by the eMotion program following registration. Where possible, brief administrative/motivational support via a 10-minute phone call was provided at week 2 .

Key content related to the rationale of BA was front loaded in the introduction, week 1 , and week 2 and was considered the "minimum dose." The remaining weekly modules (weeks 3-8) were shorter and designed to support people to review and update their plans. The intervention supports "effective engagement" and self-regulation by encouraging people to review their plans weekly, irrespective of whether or not they continue to login (eg, using their own diaries).

\section{eMotion Development}

The content for eMotion was developed by the study authors (JDL, CJG, PF, AMH, and AHT). The Living Life to the Full Web-based platform was used to host the intervention. eMotion was adapted from the BAcPAc intervention [22,23] using the Centre for eHealth Research and Disease Management (CeHReS) roadmap [35]. The CeHReS roadmap is intended to help the planning, coordination, and execution of the participatory development process of eHealth. In eMotion, this involved using patient and public involvement, usability testing, and a structured literature search. A full description of the eMotion intervention and its developmental process was previously provided [36].

\section{Control (Waiting List)}

Participants in the control group did not receive the eMotion intervention but were able to access usual care as normal. After 
data collection at the 2-month time point, participants were given access to and instructions for using eMotion. No eMotion facilitator support was provided, although participants could contact the lead researcher for (nonclinical) support if they experienced any difficulties using the intervention.

Table 1. eMotion structure.

\begin{tabular}{|c|c|c|}
\hline Steps & Content & Module in eMotion \\
\hline Step 1: Provide a rationale & $\begin{array}{l}\text { People are provided with a full and comprehensive rationale for behavioral activation } \\
\text { and } \mathrm{PA}^{\mathrm{a}} \text {, including reference to the interaction of physiological, behavioral, and } \\
\text { cognitive emotional symptoms, the role of avoidance in maintaining low mood and } \\
\text { the idea of routine, pleasurable, necessary, and activities (including PA). }\end{array}$ & Introduction and Week 1 \\
\hline Step 2: Identify activities & $\begin{array}{l}\text { People are helped to identify routine, pleasurable, and necessary activities (including } \\
\text { PA) - things that they would like to do but have usually stopped doing since they } \\
\text { became depressed. }\end{array}$ & Weeks 2-8 \\
\hline Step 3: Make a hierarchy of activities & $\begin{array}{l}\text { People are helped to organize the activities into a hierarchy of difficulty-most } \\
\text { difficult, medium difficult, and easiest. People should include some of each type } \\
\text { of routine, pleasurable, and necessary activity (including PA). }\end{array}$ & Weeks 2-8 \\
\hline Step 4: Plan some activities & $\begin{array}{l}\text { eMotion helps people to schedule some avoided activities into their week, to spec- } \\
\text { ify a mixture of routine, pleasurable, and necessary activities (including PA). These } \\
\text { should be initially identified from the "easiest" category of their hierarchy from } \\
\text { step 3). Activities should be detailed precisely: what, where, when, and with whom. }\end{array}$ & Weeks 2-8 \\
\hline Step 5: Implement activities & $\begin{array}{l}\text { People are encouraged to undertake the planned activities. The principle of grading } \\
\text { activities and using a mixture of routine, pleasurable, and necessary activities (in- } \\
\text { cluding PA) should be followed. People should record if they accomplished the } \\
\text { planned activity. }\end{array}$ & Weeks 2-8 \\
\hline Step 6: Review progress & $\begin{array}{l}\text { People are encouraged to reflect on their progress, congratulating themselves for } \\
\text { success and overcoming any problem-solving difficulties experienced during im- } \\
\text { plementation. People may make sporadic progress and activities may not go as } \\
\text { planned. }\end{array}$ & Weeks 3-8 \\
\hline
\end{tabular}

${ }^{\mathrm{a} P A:}$ Physical activity.

\section{Feasibility Outcomes}

\section{Recruitment and Attrition}

Participant recruitment rates were derived by calculating the absolute number of people randomized in the trial relative to those who expressed an initial interest in the study. Participant attrition was defined as the percentage of randomized participants who began the intervention but failed to provide primary outcome data (PHQ-8) at the 2-month data collection point.

\section{Feasibility of Data Collection}

Feasibility of data collection was explored by assessing the percentage of Web-based screening, baseline, and 2-month postrandomization questionnaires that were completed, as intended. For accelerometers, the percentage of devices that were returned at baseline and at 2 months follow-up as well as the amount of valid wear time were assessed. Reasons for any missing data were tabulated, where available.

\section{Primary Outcome for the Planned Future Trial}

\section{Depression}

The PHQ-8 was delivered at screening and at 2 months postrandomization using a Web-based self-completed version of the questionnaire. The PHQ-8 is a freely available 8 -item self-report measure based on the symptoms of depression described in the Diagnostic and Statistical Manual for Mental Disorders (DSM-IV). It measures the frequency of depressive symptoms over the preceding 2-week period. A score of at least 10 on the PHQ- 8 has a positive likelihood ratio of 28 for detecting major depression (ie, a patient with any depressive disorder is 28 times more likely to have a PHQ-8 score of 10-24 than someone without a depressive disorder) [37]. Each item is rated on a scale of 0-3, producing a range of scores from 0-24 (0-4=no depression, 5-9=mild depression, 10-14=moderate depression, 15-19=moderately severe depression, and 20-24=severe depression). The PHQ-8 has good validity, reliability, sensitivity, and specificity [37] and has been used in previous Web-based intervention studies of low mood and depression [38].

\section{Secondary Outcomes for the Planned Future Trial}

\section{Objective Physical Activity}

GENEActiv accelerometers (Activeinsights Ltd., Kimboloton, Cambs, UK) were used to record PA at baseline and at 2-months postrandomization. The GENEActiv is a small wrist-worn device that measures and records acceleration. It was set to record at $100 \mathrm{~Hz}$. Data were downloaded using the GENEActiv PC software (version 2.9) and processed in R (https://cran.r-project.org/) using package GGIR (version 1.2-8) $[39,40]$. Raw data were used to create a vector magnitude $\sqrt{ }\left(x^{\wedge} 2+y^{\wedge} 2+z^{\wedge} 2\right)-1 g$ negative numbers were rounded to 0 to create the Euclidean Norm minus one (measured in $\mathrm{mg}$ ), as previously reported [41]. Data were averaged over 5-s epochs. Nonwear was assessed over a 60-minute window, using moving 15-minute increments [42] if the standard deviation of 2 of the 
3 axes were less than $13 \mathrm{mg}$ and the value range was less than $50 \mathrm{mg}$. Participants were mailed the device before randomization and instructed to wear it continuously on their nondominant hand for 7 days from the following morning, without changing their routine PA. To be considered valid for analysis, data were needed for at least 4 days with a minimum of $10 \mathrm{~h}$ per day, including at least 1 day on the weekend. Published thresholds were used to determine average daily minutes of activity in light (LPA), moderate (MPA), vigorous (VPA), and moderate and vigorous (MVPA) intensities [43]. Minutes of activity accumulated in 10-minute bouts were established using an $80 \%$ rule, where activity must be sustained above the appropriate threshold for at least $80 \%$ of the time [42].

\section{Self-Reported Physical Activity}

Minutes per week of MVPA were estimated using Web-based self-completion of the International PA Questionnaire-Short Form (IPAQ-SF) at baseline and at 2-months postrandomization. The IPAQ-SF is a validated measure of PA [44] and has been used in previous behavioral trials promoting PA for depression $[29,45]$ as well as being the most frequently used measure in Web-based studies for PA [46].

\section{Anxiety}

The General Anxiety Disorder scale (GAD-7) is a 7-item, 4-point scale (0-3) and was used to assess anxiety using Web-based self-completion at baseline and at 2-months postrandomization. The GAD-7 measures the severity of anxiety symptoms over the past 2 weeks based on the DSM-IV criteria. The GAD-7 has good reliability as well as criterion, construct, factorial, and procedural validity. At the cutoff point of 10, the GAD-7 has a sensitivity of $89 \%$ and specificity of $82 \%$ [37].

\section{Demographic Data}

Data on age, gender, level of education (GCSE, A-levels, degree, postgraduate, or doctoral), employment status (full-time, part-time, homemaker, student, retired, or unemployed), current receipt of psychotherapy (yes or no), current receipt of antidepressants (yes or no), method of recruitment (social media, newspaper, word of mouth, or other), and ethnicity were collected at baseline using a Web-based questionnaire.

\section{Fidelity}

As recommended in previous studies [25,47], intervention fidelity was conceptualized and measured in the domains of design fidelity, training fidelity, quality/completeness of delivery, participant receipt, and enactment. The process of establishing good design fidelity for the eMotion intervention was previously reported [36]. However, given that the eMotion intervention had very limited external human support, training fidelity was not applicable in this study. Delivery fidelity was assessed using website usage statistics from the Web-based intervention database. This database provided individual level data about whether the participant registered for eMotion, modules accessed, and the total time spent on each module. Participant receipt and enactment of the intended intervention processes were measured using Web-based questionnaires. For fidelity of receipt, 2 approaches were used. The first approach assessed participants' understanding of how emotions, behaviors, thoughts, and physical feelings affect each other to maintain depression over time. A single item was used based on questions used in a previous study [48]. The item employed a 5-point Likert response scale (Strongly Agree to Strongly Disagree) assessing participant agreement with the following statement: "I understand how emotions, behaviors, thoughts, and physical feelings affect each other to maintain depression over time." The second approach assessed participants' perceived ability to use the intended BCTs. This was assessed by asking participants to rate their confidence in using specific BCTs (ie, identification of suitable activities, grading activities for ease of use, and planning and dealing with setbacks) over the last 2 months on a scale from 1 (not at all confident) to 10 (very confident). This measure was adapted from measures of confidence used in the ProActive trial [49]. Finally, to assess enactment, we asked participants if they had used specific BCTs related to BA in the last 2 months using a binary scale (yes/no). This measure was adapted from similar measures of BCT usage showing that enactment was significantly associated with weight loss, providing initial evidence of the validity of this type of measure [50].

\section{Acceptability}

The Client Satisfaction Questionnaire-Short Form (CSQ-SF) is a 4-item measure and was used to assess participant satisfaction regarding their use of eMotion 2 months postrandomization (given to intervention participants only). This measure was administered using a Web-based questionnaire and has been used to assess treatment satisfaction in other studies of Web-based interventions for depression [51].

\section{Sample Size}

Due to the pilot nature of the study, no formal sample size calculations were conducted. However, to ensure a suitably reliable estimate of the standard deviations to power a future trial with $90 \%$ power, at least 15 people per arm were recommended if the expected effect size was to be between 0.3 and 0.7 [52]. A previous meta-analysis of computer-based psychological treatments for depression reported a moderate effect size (0.56) and a drop-out rate of 57\% [38]. As such, a target sample size of 62 was adopted (accounting for a possible attrition rate of $50 \%$ ) to ensure at least 15 people per arm at follow-up.

\section{Randomization}

Once participants completed the baseline assessment, they were randomly allocated to either the intervention or control group using simple randomization at the individual level in a 1:1 ratio and a Web-based randomization service (Sealed Envelope Ltd. 2016). Personal details were anonymized through the use of participant numbers that were entered into the website by the lead author in a consecutive manner (in the order of completed baseline assessment), and the randomization service allocated them to either group A (eMotion) or group B (waiting list) without any stratification.

\section{Blinding}

Due to limited resources for the study, the lead author was not blinded to which condition each participant was allocated following randomization. Due to the nature of the intervention, it was also impossible to blind participants to group allocation. 
However, because outcome measures were taken using Web-based self-report surveys, there was a reduced chance of the lead author influencing the participant's responses or for the lead author to misinterpret responses or introduce subjective bias into recorded observations [53].

\section{Statistical Analysis}

Quantitative methods were used to explore the following: recruitment and attrition rates of trial participants; feasibility of data collection and study procedures; baseline data (including levels of PA and baseline differences between groups and between dropouts); and fidelity of delivery. Descriptive statistics were produced for all outcomes by trial arm at baseline and 2-month follow-up. All quantitative analyses were conducted using Stata SE statistical software release 14 (StataCorp. 2015; College Station, TX). No formal hypothesis testing relating to primary outcomes was planned because this was a pilot study. However, descriptive statistics were used to assess recruitment and retention rates and baseline PA levels. Baseline demographic and clinical characteristics were descriptively presented as proportions or as means with standard deviations. Two types of exploratory analyses of the primary outcome (PHQ-8) were conducted: 1) linear regression models to report changes in depression with $95 \%$ confidence intervals around the between-group mean difference and 2) logistic regression models that dichotomized the primary outcome to reflect clinically meaningful change (a reduction to below 10 on the PHQ-8 indicated that the person may no longer qualify for major depression) [37]. The analyses were conducted on participants with complete data only, which included those who began treatment and provided follow-up data regardless of treatment compliance. Missing data were not imputed. Similar analyses were conducted for anxiety, objective, and self-reported PA. We conducted sensitivity analyses using linear regression models to examine the effects of receiving psychological therapies as well as any substantial differences in baseline characteristics on the findings. We also analyzed the mean reduction in depressive symptoms for those who received the minimum dose of intervention and provided data at 2 months postrandomization.

\section{Ethics}

This study was approved by the University of Exeter Sports and Health Sciences Research Ethics Committee (AM160316-21 $151021 / \mathrm{B} / 03)$. One possible ethical issue in this study was suicide risk in people experiencing depression. Because this was a research study on a nonclinical sample, all participants were advised on the PIS that the study was not a clinical or NHS treatment and that the University and researchers could not take clinical responsibility for the treatment of any conditions they might have including depression. They were also signposted to other appropriate resources in case they wished to seek formal treatment. If, at any point in the study (eg, while on the phone to a researcher during screening or after inclusion), participants indicated suicidal intent, the University of Exeter Mood Disorders Suicide Risk Protocol was invoked.

\section{Results}

\section{Participant flow}

A total of 183 people responded to the adverts, with 100 completing screening for eligibility (Figure 1). Of the 183 individuals who initially inquired about the study, 100 were still interested and screened for eligibility and 62 (34\% of those who initially enquired [95\% CI 27-41] and 62\% (62/100) of those who were screened [95\% CI 52-71]) were eligible for inclusion and randomized in the trial between May 2016 and February 2017 (32 in the eMotion group, 30 in the control group). Overall attrition in relation with the planned main trial primary outcome (PHQ-8) at 2 months postrandomization was $19 \%$ (12/62; 95\% CI 11-31). Of those randomized, 94\% (58/62) of participants provided complete secondary outcome baseline measurements (eg, GAD7, IPAQ-SF) and 84\% (52/62) provided usable accelerometer data at baseline. At 2-month follow-up, $81 \%(50 / 62)$ of those randomized [95\% CI 71-91] provided PHQ-8 (and other survey data) and 39\% (24/62) of those randomized [95\% CI 27-52] provided valid accelerometer data. Only 76\% (47/62) and 53\% (33/62) participants provided valid IPAQ-SF data at baseline and 2 months postrandomization, respectively. This lack of usable IPAQ-SF data was due to people providing invalid responses.

\section{Feasibility of Accelerometer Data Collection}

At baseline, 6 accelerometers were not sent out due to participants not responding to the request confirming their willingness to wear it or not being willing /able to wear it. Three accelerometers had data processing problems (technical failure). At follow-up, missing accelerometer data were primarily due to participants not responding to the request to wear the device again $(n=13)$ or participants being lost to follow-up (not responding in any way; $n=9$ ).

\section{Baseline Demographic and Clinical Characteristics}

At baseline (Table 2 and Table 3), the mean age was 38 years with women accounting for $84 \%$ (52/62) of all participants, and $97 \%$ (60/62) of participants were white British. Nearly half the sample was recruited through social media (Facebook or Twitter) with the second most popular method being "word of mouth" (ie, hearing about the study from friends or family). Participants had a range of educational levels, and most (55/62, $89 \%$ ) of them were employed either part-time or full-time. The mean score on the PHQ-8 was 14.6 (SD 3.2), and the mean score on the GAD-7 was 11.8 (SD 4.5). All PA data were positively skewed; hence, medians and interquartile ranges were reported. The median daily total minutes of accelerometer-measured PA was 174.3 (IQR 136.8-212.5) for light PA (LPA), 53.5 (IQR 39.8-80.7) for moderate PA (MPA), 2.9 (IQR 1.0-6.2) for vigorous PA (VPA), and 55.2 (IQR 40.9-90.7) for moderate and vigorous PA (MVPA). The median weekly total minutes of accelerometer-measured MVPA in at least 10-minute bouts was 35.8 (IQR 0.0-98.6). Only 13\% (7/52) people achieved at least 150 minutes per week of MVPA in at least 10-minute bouts. The median level of daily self-reported MVPA was 12.9 minutes (IQR 0.0-25.7). Over half (36/62, $58 \%$ ) of the participants were receiving antidepressants, and $13 \%(8 / 62)$ were receiving some form of psychotherapy, with 
a higher proportion receiving therapy in the control group (7/30, Finally, the intervention group was older by 2 years with a mean $23 \%)$ than in the intervention group $(1 / 32,3 \%)$. The intervention of 39.3 (12.0) years compared with 36.9 (12.6) years in the group had a higher median of total MVPA per day (71 min, control group. IQR 46.7-85.9) than the control group (55 min, IQR 40.1-90.7).

Figure 1. CONSORT flow chart.

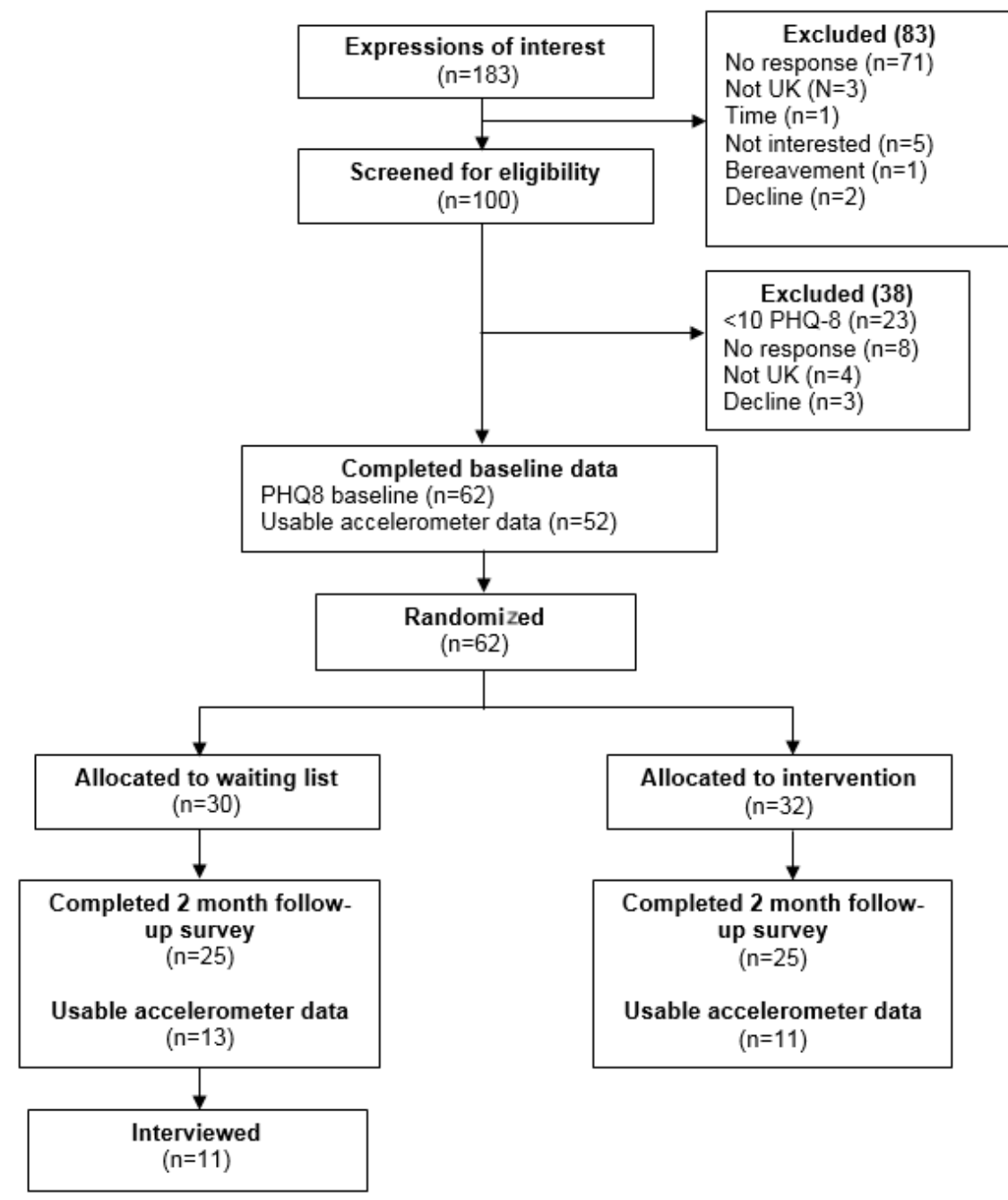

Table 2. Participant demographic and clinical characteristics at baseline.

\begin{tabular}{|c|c|c|c|c|c|c|}
\hline \multirow[t]{2}{*}{ Characteristics } & \multicolumn{2}{|c|}{ eMotion } & \multicolumn{2}{|c|}{ Control group } & \multicolumn{2}{|c|}{ Whole sample } \\
\hline & $\mathrm{N}$ & Mean (SD) & $\mathrm{N}$ & Mean (SD) & $\mathrm{N}$ & Mean (SD) \\
\hline Age in years & 32 & $39.3(12.0)$ & 30 & $36.9(12.6)$ & 62 & $38.1(12.3)$ \\
\hline Depression (PHQ-8 ${ }^{\mathrm{a}}$ ) & 32 & $14.4(3.5)$ & 30 & $14.8(2.9)$ & 62 & $14.6(3.2)$ \\
\hline Anxiety $\left(\mathrm{GAD}-7^{\mathrm{b}}\right)$ & 31 & $11.5(4.7)$ & 27 & $12.3(4.2)$ & 58 & $11.8(4.5)$ \\
\hline Min per week of objective MVPA $^{c}$ in 10-min bouts ${ }^{\mathrm{d}}$ & 27 & $29.5(0.0-98.8)$ & 25 & $42.1(8.1-93.7)$ & 52 & $35.8(0.0-98.6)$ \\
\hline IPAQ-SF daily min of MVPA ${ }^{\mathrm{d}}$ & 27 & $12.9(0.0-25.7)$ & 20 & $10.7(3.6-17.9)$ & 47 & $12.9(0.0-25.7)$ \\
\hline
\end{tabular}

${ }^{\mathrm{a}}$ PHQ-8: Patient Health Questionnaire 8.

${ }^{\mathrm{b}}$ GAD-7: General Anxiety Disorder scale.

${ }^{c}$ MVPA: moderate-to-vigorous intensity physical activity.

${ }^{\mathrm{d}}$ Data were positively skewed, so medians (interquartile ranges) are reported. 
Table 3. Participant demographic and clinical characteristics at baseline.

\begin{tabular}{|c|c|c|c|c|c|c|}
\hline \multirow[t]{2}{*}{ Characteristics } & \multicolumn{2}{|c|}{ eMotion } & \multicolumn{2}{|c|}{ Control Group } & \multicolumn{2}{|c|}{ Whole Sample } \\
\hline & $\mathrm{N}$ & $\mathrm{n}(\%)$ & $\mathrm{N}$ & $\mathrm{n}(\%)$ & $\mathrm{N}$ & $\mathrm{n}(\%)$ \\
\hline Female & 32 & $26(81)$ & 30 & $26(87)$ & 62 & $52(84)$ \\
\hline Receiving therapy & 32 & $1(3)$ & 30 & $7(23)$ & 62 & $8(13)$ \\
\hline Antidepressants & 32 & $18(56)$ & 30 & $18(60)$ & 62 & $36(58)$ \\
\hline$>150$ m per week of MVPA $^{\mathrm{a}}$ (10-min bouts) & 27 & $3(11)$ & 25 & $4(16)$ & 52 & $7(13)$ \\
\hline Currently employed, studying, or training & 32 & $28(88)$ & 30 & $27(90)$ & 62 & $55(89)$ \\
\hline Educated to A level or beyond & 32 & $25(78)$ & 30 & $23(77)$ & 62 & $48(77)$ \\
\hline
\end{tabular}

${ }^{a}$ MVPA: moderate-to-vigorous intensity physical activity.

\section{Intervention fidelity}

In total, $88 \%(28 / 32)$ of the intervention participants registered for eMotion and began the introduction module. The median number of logins, modules accessed, and total minutes spent on eMotion was 3 (IQR 2-8), 3 (IQR 2-5), and 41.3 (IQR 18.9-90.4), respectively. Overall, 53\% (17/32) of participants completed at least the introduction, week 1 , and week 2 , and $25 \%(8 / 32)$ of participants completed up to at least week 4. Only one participant used every module. Of the 46 participants who provided receipt and enactment data at both baseline and 2 months postrandomization, those randomized to the eMotion group reported a significant difference, compared with the control group, in levels of understanding about how thoughts, feelings, and behaviors affect mood (adjusted mean difference $0.5,95 \%$ CI -0.0 to -1.0 ). Significant differences were also found for confidence to identify (adjusted mean difference 1.4, 95\% CI 0.0-2.8), select (adjusted mean difference 1.3, 95\% CI -0.02 to 2.6 ), and plan (adjusted mean difference $1.8,95 \% \mathrm{CI}$ 0.5-3.1) achievable activities to improve mood as well as confidence to deal with setbacks (adjusted mean difference 1.5, $95 \%$ CI 0.2-2.7). Of the participants who answered "no" on the enactment questionnaires at baseline, those who were randomized to the eMotion group were significantly more likely to select $(\mathrm{N}=25$; OR $10,95 \%$ CI 1.6-62.7) and plan $(\mathrm{N}=33$; OR $10.3,95 \%$ CI $2.0-52.6)$ activities to improve their mood at the 2-month follow-up.

\section{Acceptability}

Of the participants randomized to receive the eMotion intervention who provided follow-up data, $4 \%$ (1/25) felt almost all their needs had been met, $32 \%(8 / 25)$ felt most of their needs had been met, $52 \%(13 / 25)$ felt only a few of their needs had been met, and $12 \%(3 / 25)$ felt none of their needs had been met. Twenty-four percent $(6 / 25)$ said they would definitely use the program again, 32\% (8/25) said "Yes I think so," 40\% (10/25) said "No, I don't think so," and 4\% (1/25) said "Definitely not." Finally, 16\% (4/25) said they were "Very Satisfied," $40 \%$ (10/25) said they were "Mostly Satisfied," 40\% (10/25) said they were "Indifferent or Mildly Satisfied," and 4\% (1/25) said they were "Quite Dissatisfied."

\section{Exploratory Analysis of Outcomes}

Exploratory analyses carried out on complete data (Table 4) showed that at 2 months postrandomization, the intervention group had a larger reduction in depressive symptoms than the control group (adjusted mean difference $-3.6,95 \% \mathrm{CI}-6.1$ to $-1.1)$. In the intervention group, $56 \%$ (14/25) of depression scores went below the threshold of 10 on the PHQ-8, compared with $28 \%$ (7/25) in the control group (OR 3.3, 95\% CI 1.0-10.6). For those who completed the minimum dose of intervention and provided data at 2 months postrandomization $(n=15)$, the mean reduction in depressive symptoms was 5 points (SD 5.4). For those who did not complete the minimum dose of intervention and provided data at 2 months postrandomization $(n=9)$, the mean reduction in depressive symptoms was 4.9 points (SD 4.6). Of the 47 participants who provided anxiety scores at both baseline and 2 months postrandomization, there was a larger reduction in symptoms of anxiety for the eMotion group than the control group (adjusted mean difference -3.3 , $95 \%$ CI -5.4 to -1.2 ). Linear regression analysis on complete data, controlling for baseline PA, revealed no between-group differences in PA at any intensity. Valid IPAQ-SF data were available for 33 trial participants at 2 months postrandomization. Linear regression analysis controlling for baseline PA revealed no between-group differences in self-reported PA.

\section{Sensitivity analysis}

When receipt of other psychological therapies was entered into the regression analysis as a covariate, the impact of co-treatment was not significant, and the intervention group still had a higher reduction in depressive symptoms than the control group (adjusted mean difference $-3.3,95 \% \mathrm{CI}-5.9$ to -0.7 ). Other baseline covariates (age, gender, employment, education level, and antidepressant usage) that may have influenced depression scores were also entered in the regression model together. Findings indicated that none of these variables had a significant covariate effect on depression scores and that the residual difference between groups was still significant (adjusted mean difference $-3.1,95 \% \mathrm{CI}-5.7$ to -0.5$)$. Within the intervention group, linear regression analyses revealed no significant relationships between numbers of modules accessed, number of logins, or total minutes spent on the website with depression outcomes. The pattern of change scores within each group is shown in Figure 2. 
Table 4. Between-group changes in primary and secondary outcomes.

\begin{tabular}{|c|c|c|c|c|c|}
\hline \multirow[t]{2}{*}{ Outcomes } & \multicolumn{2}{|c|}{ eMotion } & \multicolumn{2}{|c|}{ Control group } & \multirow[t]{2}{*}{ Adjusted mean difference $^{\mathrm{a}}(95 \% \mathrm{CI})$} \\
\hline & $\mathrm{N}$ & Mean (SD) & $\mathrm{N}$ & Mean (SD) & \\
\hline Baseline & 32 & $14.4(3.4)$ & 30 & $14.8(2.9)$ & \\
\hline 2 months postrandomization & 25 & $8.7(4.8)$ & 25 & $12.9(4.2)$ & $-3.6(-6.1$ to -1.1$)$ \\
\hline \multicolumn{6}{|l|}{ Anxiety (GAD-7 ${ }^{\mathrm{c}}$ ) } \\
\hline Baseline & 31 & $10.1(5.4)$ & 27 & $12.0(4.7)$ & \\
\hline 2 months postrandomization & 25 & $7.1(3.8)$ & 25 & $10.9(3.7)$ & $-3.3(-5.4$ to -1.2$)$ \\
\hline \multicolumn{6}{|c|}{ Min per week of objective MVPA in 10-min bouts ${ }^{d}$} \\
\hline Baseline & 27 & $29.5(0.0$ to 8.8$)$ & 25 & $42.1(8.1$ to 93.7$)$ & \\
\hline 2 months postrandomization & 13 & $97.6(49.7$ to 166.3$)$ & 11 & $13.0(0.0$ to 131.4$)$ & $16.4(-43.7$ to 76.5$)$ \\
\hline \multicolumn{6}{|l|}{ IPAQ-SF daily minutes of MVPA $^{d}$} \\
\hline Baseline & 27 & $12.9(0.0$ to 25.7$)$ & 20 & 10.7 (3.6 to 17.9$)$ & \\
\hline 2 months postrandomization & 19 & 11.4 (4.3 to 25.7$)$ & 14 & $15.7(0.0$ to 22.9$)$ & $0.2(-8.7$ to 9.2$)$ \\
\hline
\end{tabular}

${ }^{\mathrm{a}}$ Multiple regression adjusted for baseline value and confidence intervals reported.

${ }^{\mathrm{b}} \mathrm{PHQ}-8$ : Patient Health Questionnaire 8.

${ }^{\mathrm{c}}$ GAD-7: General Anxiety Disorder scale.

${ }^{\mathrm{d}}$ As physical activity data were skewed, medians and interquartile ranges (IQR) are presented, and analysis was repeated using bootstrapping.

Figure 2. PHQ-8 change scores for individual participants.

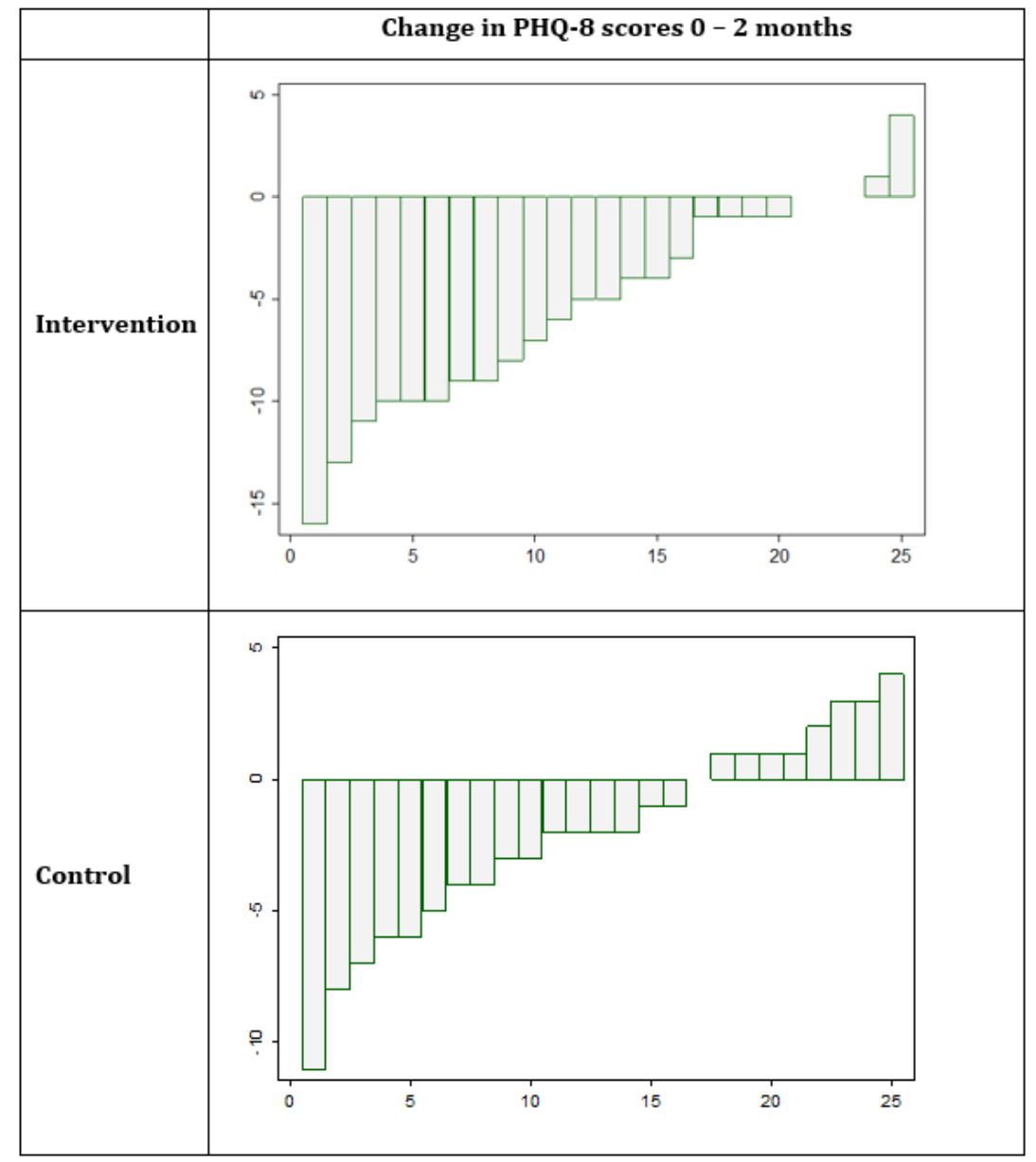




\section{Discussion}

\section{Summary of Findings}

The present study examined the feasibility of conducting an RCT of the eMotion intervention. We successfully recruited a less-active population with elevated depression and anxiety. The trial also had acceptable attrition rates concerning the primary outcome at 2 months. Concerning the feasibility of data collection, most people provided valid accelerometer data at baseline. However, there was a lack of valid accelerometer data at 2 months postrandomization. The baseline level of MVPA in 10-minute bouts was low, with only $13 \%$ (7/52) of participants achieving at least 150 minutes of MVPA per week. Of those randomized to the intervention group, most people registered for eMotion and just over half completed the "minimum dose" (introduction, week 1, and week 2). Exploratory analyses revealed larger changes in depressive symptoms and anxiety in the eMotion group than those in the control group at 2 months postrandomization. Descriptive PA data revealed a higher weekly median of minutes of MVPA in 10 -minute bouts per week in the eMotion group than in the control group at 2 months postrandomization. This difference was not significant, although this may reflect low numbers available for analysis and high variance in this measure.

\section{Relationship to Other Literature}

The achieved recruitment rates resembled those found in other studies of Web-based interventions promoting PA for depression [29-31,45,54]. Other studies report between $26 \%$ and $46 \%$ of people approached being subsequently randomized [29-31,45,54]. Mailey et al [54] recruited students registered with mental health counseling services but did not have an inclusion criterion for the level of depressive symptoms, possibly contributing to their higher recruitment rate (46\%).

Our retention rate compared well with other self-delivered trials of psychological and PA interventions for depression [30]. A recent 3-arm RCT comparing administratively supported Web-based BA, PA, and a waiting list control group had a similar retention rate to ours at 8 weeks postrandomization (82\%) [30]. Conversely, a systematic review of Web-based psychological treatments for depression reported drop-out rates of $74 \%$ for unsupported, $38.4 \%$ for administratively supported, and $28 \%$ for therapist-supported treatments [38]. Some individual trials of Web-based PA interventions for depression have reported lower attrition rates than ours $(8 \%-12 \%)[29,54]$. However, both of these trials provided therapist support, whereas our study only provided administrative support. Our data, combined with previous research, suggested that a low level of administrative support may be adequate to retain acceptable numbers of participants at follow-up.

Most studies investigating the effect of PA on depression conceptualize PA as a prescribed structured intervention and have not previously measured baseline levels or changes in PA $[6,8]$. Also, change in PA has typically not been measured or reported in trials of psychological treatments for depression [55]. This is one of the few intervention studies to collect baseline PA data (using objective measures) in people with elevated depressive symptoms, building on other recent intervention studies following a similar approach [56].

With a baseline median of 35.8 (IQR 0.0-98.6) minutes per week of MVPA (in at least 10-minute bouts), we appear to have recruited a less-active sample than other similar studies. For example, a recent cross-sectional study $(n=165)$ of adults with depression ( $\geq 10$ on the PHQ-9) reported a baseline mean of 18.2 (SD 17.4) minutes of MVPA (in 10-minute bouts) per day [57]. One possible explanation for this is that the clear indication of "exercise" in the PIS attracted people with depression who were already active [57]. In eMotion, however, the intervention was not overtly presented as exercise, but rather as a behavioral intervention to promote routine, pleasurable, and necessary activities (which could include PA).

The current guidelines for PA (150 minutes of MVPA per week) are based on improving and maintaining physical health, rather than mental health [58]. The dose of PA for improving and maintaining mental health is not clear and may well be linked to the quality of the experience rather than just the physical volume. For example, a recent longitudinal cohort study $(n=33,908)$ suggests that $12 \%$ of future cases of depression could be prevented with just 60 minutes of any intensity PA per week [59].

Only $56 \%$ of the participants in the intervention arm accessed at least the introduction, week 1 , and week 2 (minimum dose), suggesting that more could be done to draw potential users into the website. eMotion actively encouraged participants to engage with the process of BA in their day-to-day lives (eg, planning and reviewing goals using their diaries). This was reflected in our process measures of receipt and enactment showing that despite the relatively low usage statistics, people randomized to eMotion were more confident to identify, select, and plan activities to improve their mood as well as to deal with setbacks (ie, to engage in the key processes of behavior change proposed by the eMotion logic model) [36]. This explanation is consistent with a recent observational study $(n=8993)$ of a Web-based handwashing intervention (PRIMIT) [60]. In PRIMIT, the largest change in behavior occurred after the first session, with incrementally smaller changes occurring after each subsequent session [60]. Taken together, these findings suggest that usage metrics reveal little about offline engagement with intervention processes and that usage cessation could either indicate disengagement from the intervention or the development of sufficient mastery [61].

Exploratory analysis revealed a decrease in symptoms of depression and anxiety in favor of the intervention group at 2 months postrandomization, a similar reduction to that found in previous studies promoting PA for depression [23,29-31,45] and anxiety [13]. However, other studies did not find such an effect $[54,62,63]$, possibly due to low power and the use of active control conditions [7]. Our findings tentatively support the utility of using BA as a more-general treatment for depression and anxiety and are consistent with findings from a large-scale RCT that found BA to be no less effective than cognitive behavioral therapy for treating depression [64]. However, it is important to note that due to its low power, 
definitive conclusions around effectiveness cannot be made from the current study.

\section{Strengths and Limitations}

This is the first study to evaluate the feasibility of delivering $\mathrm{BA}$ in combination with the explicit promotion of PA, in a Web-based format. The main strength of this study was the use of rigorous methods to assess the feasibility of conducting a full-scale RCT. We used objective methods to assess PA and validated self-report measures of depression and anxiety symptoms. However, several limitations of this study need to be acknowledged.

As observed in other large-scale depression trials, our sample did not represent the wider UK population, particularly in terms of ethnicity and gender [64,65]. This is most likely an artifact of our recruitment method (ie, community recruitment) and target location (South West England). However, there are other individual factors including ability to recognize and accept mental health problems, positive impact of social networks, reluctance to discuss psychological distress and seek help among men, cultural identity, perceived social stigma against mental health, and financial factors [66]. A larger trial could attempt to recruit a more representative sample by targeting locations with more culturally diverse populations. Tailored recruitment approaches could also be used to address individual barriers to engagement (eg, using adverts targeted at males).

Although we randomized participants, due to a lack of resources for independent data collection, there was no blinding, which could have led to an inflation of the observed effects [67]. However, the potential for researcher bias was limited in this case due to an absence of any face-to-face contact when collecting outcome measures. Our groups were imbalanced at baseline with regard to co-interventions. However, these factors did not seem to strongly impact the findings. A future trial could remedy this either by including therapy as a randomization-minimization variable or adding it as an exclusion criterion.

Due to resource issues, "minimal contact" administrative support was provided by the lead author. It is possible that this may have led to bias when collecting outcomes. However, because the outcomes were collected via self-administered Web-based questionnaires and accelerometers, this is unlikely to have had an effect. We would still recommend using independent supporters in the main trial for practical reasons and for testing the feasibility of providing such support in a "real-world" NHS context, if the intervention proves effective in a full-scale RCT.

A further limitation is that the PHQ-8 was used rather than the more conventional PHQ-9. The PHQ-8 was chosen due to the lack of any directly available clinical surveillance or support for participants, as it would not have been feasible to follow-up any (Web-based) survey responses expressing suicidal ideation in response to PHQ item 9 with an immediate telephone interview. The PHQ-8 is specifically recommended for use in such circumstances [37]. Furthermore, the PHQ-8 is very similar to the PHQ-9 and has excellent convergent validity ( $r=0.997)$, indicating that the 2 scales are comparable [68].

\section{Implications for Future Research}

Future studies should refine procedures (as indicated above) and further develop the eMotion intervention to optimize user engagement and experiences. Despite exploratory data showing modest reductions in depression and anxiety, only half of the people who used eMotion were mostly or very satisfied with their experience. Qualitative interviews performed on a sample of participants $(n=11)$ have helped to identify barriers and facilitators to engaging with the intervention and with the trial (including the use of accelerometers) and suggest ways to maximize data collection and minimize attrition. This data will be reported in detail elsewhere. Refinements of the study procedures would also be needed to collect more complete and meaningful data on PA in any future trial. This could be achieved via face-to-face contact or by providing incentives.

In line with the MRC framework [69], large, well-controlled RCTs that build on the findings from this pilot trial could help to more definitively test whether such an intervention is effective in reducing depression and increasing $\mathrm{PA}$ in community-dwelling populations with depression in the UK and elsewhere.

\section{Conclusion}

The eMotion intervention is novel in attempting to offer an integrated solution to the 2 critical public health priorities of depression and lack of PA. Based on the data presented, both the eMotion intervention and methods needed to conduct a trial seem to be feasible and acceptable. If successful in a large-scale trial, eMotion would have the potential to reduce depression and anxiety symptoms for people in the community, easing the burden on NHS resources. There may also be further potential to increase PA in this population.

\section{Acknowledgments}

JDL's time input was supported by the Economic and Social Research Council (ESRC Grant Number: ES/J50015X/1). This report is independent research and the views expressed are those of the authors and not necessarily those of National Institute for Health Research (NIHR) or the UK Department of Health. At the time of manuscript submission, AHT is funded by the NIHR Health Technology Assessment Program (ref: 15/111/01; ref 13/25/20), the NIHR Public Health Research Program (14/54/19), the NIHR Research for Patient Benefit Program, and the Medical Research Council, intervention development program.

\section{Conflicts of Interest}

None declared. 


\section{Multimedia Appendix 1}

CONSORT-EHEALTH checklist (V 1.6.1).

[PDF File (Adobe PDF File), 1MB-Multimedia Appendix 1]

\section{References}

1. Stevenson D, Farmer P. GOV.UK. Thriving at work: The Stevenson / Farmer review of mental health and employers URL: https://assets.publishing.service.gov.uk/government/uploads/system/uploads/attachment data/file/658145/ thriving-at-work-stevenson-farmer-review.pdf[WebCite Cache ID 6zlpg6X94]

2. Ali S, Stone MA, Peters JL, Davies MJ, Khunti K. The prevalence of co-morbid depression in adults with Type 2 diabetes: a systematic review and meta-analysis. Diabet Med 2006 Nov;23(11):1165-1173. [doi: 10.1111/j.1464-5491.2006.01943.x] [Medline: 17054590]

3. Anderson RJ, Freedland KE, Clouse RE, Lustman PJ. The prevalence of comorbid depression in adults with diabetes: a meta-analysis. Diabetes Care 2001 Jun;24(6):1069-1078. [Medline: 11375373]

4. Whooley MA, de JP, Vittinghoff E, Otte C, Moos R, Carney RM, et al. Depressive symptoms, health behaviors, and risk of cardiovascular events in patients with coronary heart disease. JAMA 2008 Nov 26;300(20):2379-2388 [FREE Full text] [doi: 10.1001/jama.2008.711] [Medline: 19033588]

5. Onyike CU, Crum RM, Lee HB, Lyketsos CG, Eaton WW. Is obesity associated with major depression? Results from the Third National Health and Nutrition Examination Survey. Am J Epidemiol 2003 Dec 15;158(12):1139-1147. [Medline: 14652298]

6. Cooney GM, Dwan K, Greig CA, Lawlor DA, Rimer J, Waugh FR, et al. Exercise for depression. Cochrane Database Syst Rev 2013;9:CD004366. [doi: 10.1002/14651858.CD004366.pub6] [Medline: 24026850]

7. Ekkekakis P. Honey, I shrunk the pooled SMD! Guide to critical appraisal of systematic reviews and meta-analyses using the Cochrane review on exercise for depression as example. Mental Health and Physical Activity 2015 Mar;8:21-36. [doi: 10.1016/j.mhpa.2014.12.001]

8. Rebar AL, Stanton R, Geard D, Short C, Duncan MJ, Vandelanotte C. A meta-meta-analysis of the effect of physical activity on depression and anxiety in non-clinical adult populations. Health Psychol Rev 2015;9(3):366-378. [doi: 10.1080/17437199.2015.1022901] [Medline: 25739893 ]

9. Mammen G, Faulkner G. Physical activity and the prevention of depression: a systematic review of prospective studies. Am J Prev Med 2013 Nov;45(5):649-657. [doi: 10.1016/j.amepre.2013.08.001] [Medline: 24139780]

10. Searle A, Calnan M, Lewis G, Campbell J, Taylor A, Turner K. Patients' views of physical activity as treatment for depression: a qualitative study. Br J Gen Pract 2011 Apr;61(585):149-156 [FREE Full text] [doi: 10.3399/bjgp11X567054] [Medline: 21439172]

11. Ussher M, Stanbury L, Cheeseman V, Faulkner G. Physical activity preferences and perceived barriers to activity among persons with severe mental illness in the United Kingdom. Psychiatr Serv 2007 Mar;58(3):405-408. [doi: 10.1176/ps.2007.58.3.405] [Medline: 17325117]

12. Babyak M, Blumenthal JA, Herman S, Khatri P, Doraiswamy M, Moore K, et al. Exercise treatment for major depression: maintenance of therapeutic benefit at 10 months. Psychosom Med 2000;62(5):633-638. [Medline: 11020092]

13. Stubbs B, Vancampfort D, Rosenbaum S, Firth J, Cosco T, Veronese N, et al. An examination of the anxiolytic effects of exercise for people with anxiety and stress-related disorders: A meta-analysis. Psychiatry Res 2017 Dec;249:102-108. [doi: 10.1016/j.psychres.2016.12.020] [Medline: 28088704]

14. Gibala MJ, Little JP, Macdonald MJ, Hawley JA. Physiological adaptations to low-volume, high-intensity interval training in health and disease. J Physiol 2012 Mar 01;590(5):1077-1084 [FREE Full text] [doi: 10.1113/jphysiol.2011.224725] [Medline: 22289907]

15. Faulkner G, Taylor A. Promoting physical activity for mental health: A complex intervention? Mental Health and Physical Activity 2009 Jun;2(1):1-3. [doi: 10.1016/j.mhpa.2009.04.001]

16. Rebar AL, Taylor A. Physical activity and mental health; it is more than just a prescription. Mental Health and Physical Activity 2017 Oct;13:77-82. [doi: 10.1016/j.mhpa.2017.10.004]

17. Hopko DR, Lejuez CW, Ruggiero KJ, Eifert GH. Contemporary behavioral activation treatments for depression: procedures, principles, and progress. Clin Psychol Rev 2003 Oct;23(5):699-717. [Medline: 12971906]

18. Lejuez CW, Hopko DR, Hopko SD. A brief behavioral activation treatment for depression. Treatment manual. Behav Modif 2001 Apr;25(2):255-286. [doi: 10.1177/0145445501252005] [Medline: 11317637]

19. Richards D. Behavioural Activation. In: Bennett-Levy J, Richards D, Farrand P, Christensen H, Griffiths K, Kavanagh D, et al, editors. Oxford guide to low intensity CBT interventions. Oxford: Oxford University Press; 2010:141-150.

20. Ekers D, Webster L, Van SA, Cuijpers P, Richards D, Gilbody S. Behavioural activation for depression; an update of meta-analysis of effectiveness and sub group analysis. PLoS One 2014;9(6):e100100 [FREE Full text] [doi: 10.1371/journal.pone.0100100] [Medline: 24936656] 
21. Michie S, Richardson M, Johnston M, Abraham C, Francis J, Hardeman W, et al. The behavior change technique taxonomy (v1) of 93 hierarchically clustered techniques: building an international consensus for the reporting of behavior change interventions. Ann Behav Med 2013 Aug;46(1):81-95. [doi: 10.1007/s12160-013-9486-6] [Medline: 23512568]

22. Farrand P, Pentecost C, Greaves C, Taylor RS, Warren F, Green C, et al. A written self-help intervention for depressed adults comparing behavioural activation combined with physical activity promotion with a self-help intervention based upon behavioural activation alone: study protocol for a parallel group pilot randomised controlled trial (BAcPAc). Trials 2014 May 29;15:196 [FREE Full text] [doi: 10.1186/1745-6215-15-196] [Medline: 24886116]

23. Pentecost C, Farrand P, Greaves CJ, Taylor RS, Warren FC, Hillsdon M, et al. Combining behavioural activation with physical activity promotion for adults with depression: findings of a parallel-group pilot randomised controlled trial (BAcPAc). Trials 2015 Aug 20;16:367 [FREE Full text] [doi: 10.1186/s13063-015-0881-0] [Medline: 26289425]

24. Watkins E, Newbold A, Tester-Jones M, Javaid M, Cadman J, Collins LM, et al. Implementing multifactorial psychotherapy research in online virtual environments (IMPROVE-2): study protocol for a phase III trial of the MOST randomized component selection method for internet cognitive-behavioural therapy for depression. BMC Psychiatry 2016 Dec 06;16(1):345 [FREE Full text] [doi: 10.1186/s12888-016-1054-8] [Medline: 27716200]

25. Lambert JD, Greaves CJ, Farrand P, Cross R, Haase AM, Taylor AH. Assessment of fidelity in individual level behaviour change interventions promoting physical activity among adults: a systematic review. BMC Public Health 2017 Dec 02;17(1):765 [FREE Full text] [doi: 10.1186/s12889-017-4778-6] [Medline: 28969669]

26. Andersson G, Titov N. Advantages and limitations of Internet-based interventions for common mental disorders. World Psychiatry 2014 Feb;13(1):4-11 [FREE Full text] [doi: 10.1002/wps.20083] [Medline: 24497236]

27. Farmer C, Farrand P, O'Mahen H. 'I am not a depressed person': how identity conflict affects help-seeking rates for major depressive disorder. BMC Psychiatry 2012 Oct 02;12:164 [FREE Full text] [doi: 10.1186/1471-244X-12-164] [Medline: 23031330]

28. Carlbring P, Lindner P, Martell C, Hassmén P, Forsberg L, Ström L, et al. The effects on depression of Internet-administered behavioural activation and physical exercise with treatment rationale and relapse prevention: study protocol for a randomised controlled trial. Trials 2013 Feb 02;14:35 [FREE Full text] [doi: 10.1186/1745-6215-14-35] [Medline: 23374879]

29. Nyström MBT, Stenling A, Sjöström E, Neely G, Lindner P, Hassmén P, et al. Behavioral activation versus physical activity via the internet: A randomized controlled trial. J Affect Disord 2017 Dec;215:85-93 [FREE Full text] [doi: 10.1016/j.jad.2017.03.018] [Medline: 28319696]

30. Soucy I, Provencher M, Fortier M, McFadden T. Efficacy of guided self-help behavioural activation and physical activity for depression: a randomized controlled trial. Cogn Behav Ther 2017 Nov;46(6):493-506. [doi: 10.1080/16506073.2017.1337806] [Medline: 28644740]

31. Rosenbaum S, Newby JM, Steel Z, Andrews G, Ward PB. Online physical activity interventions for mental disorders: A systematic review. Internet Interventions 2015 May;2(2):214-220. [doi: 10.1016/j.invent.2015.04.001]

32. Eysenbach G, CONSORT-EHEALTH Group. CONSORT-EHEALTH: improving and standardizing evaluation reports of Web-based and mobile health interventions. J Med Internet Res 2011 Dec 31;13(4):e126 [FREE Full text] [doi: 10.2196/jmir.1923] [Medline: 22209829]

33. Hoffmann TC, Glasziou PP, Boutron I, Milne R, Perera R, Moher D, et al. Better reporting of interventions: template for intervention description and replication (TIDieR) checklist and guide. BMJ 2014;348:g1687 [FREE Full text] [Medline: 24609605]

34. Farrand P, Woodford J. Impact of support on the effectiveness of written cognitive behavioural self-help: a systematic review and meta-analysis of randomised controlled trials. Clin Psychol Rev 2013 Feb;33(1):182-195. [doi: 10.1016/j.cpr.2012.11.001] [Medline: 23238023]

35. van GJEWC, Nijland N, van LM, Ossebaard HC, Kelders SM, Eysenbach G, et al. A holistic framework to improve the uptake and impact of eHealth technologies. J Med Internet Res 2011;13(4):e111 [FREE Full text] [doi: 10.2196/jmir.1672] [Medline: 22155738]

36. Lambert JD, Greaves CJ, Farrand P, Haase AM, Taylor AH. Development of a web-based intervention (eMotion) based on behavioural activation to promote physical activity in people with depression. Mental Health and Physical Activity 2017 Oct;13:120-136. [doi: 10.1016/j.mhpa.2017.10.003]

37. Kroenke K, Strine TW, Spitzer RL, Williams JBW, Berry JT, Mokdad AH. The PHQ-8 as a measure of current depression in the general population. J Affect Disord 2009 Apr;114(1-3):163-173. [doi: 10.1016/j.jad.2008.06.026] [Medline: 18752852]

38. Richards D, Richardson T. Computer-based psychological treatments for depression: a systematic review and meta-analysis. Clin Psychol Rev 2012 Jun;32(4):329-342. [doi: 10.1016/j.cpr.2012.02.004] [Medline: 22466510]

39. van HVT, Gorzelniak L, Dean LEC, Eder M, Pias M, Taherian S, et al. Separating movement and gravity components in an acceleration signal and implications for the assessment of human daily physical activity. PLoS One 2013;8(4):e61691 [FREE Full text] [doi: 10.1371/journal.pone.0061691] [Medline: 23626718]

40. Sabia S, van HVT, Shipley MJ, Trenell MI, Hagger-Johnson G, Elbaz A, et al. Association between questionnaire- and accelerometer-assessed physical activity: the role of sociodemographic factors. Am J Epidemiol 2014 Mar 15;179(6):781-790 [FREE Full text] [doi: 10.1093/aje/kwt330] [Medline: 24500862] 
41. Hildebrand M, Hansen BH, Ekelund U. Age group comparability of raw accelerometer output from wrist- and hip-worn monitors. Med Sci Sports Exerc 2014 Sep;46(9):1816-1824. [doi: 10.1249/MSS.0000000000000289] [Medline: 24887173]

42. da Silva IC, van Hees VT, Ramires VV, Knuth AG, Bielemann RM, Ekelund U, et al. Physical activity levels in three Brazilian birth cohorts as assessed with raw triaxial wrist accelerometry. Int J Epidemiol 2014 Dec;43(6):1959-1968 [FREE Full text] [doi: 10.1093/ije/dyu203] [Medline: 25361583]

43. Esliger DW, Rowlands AV, Hurst TL, Catt M, Murray P, Eston RG. Validation of the GENEA Accelerometer. Med Sci Sports Exerc 2011 Jun;43(6):1085-1093. [doi: 10.1249/MSS.0b013e31820513be] [Medline: 21088628]

44. Craig CL, Marshall AL, Sjöström M, Bauman AE, Booth ML, Ainsworth BE, et al. International physical activity questionnaire: 12-country reliability and validity. Med Sci Sports Exerc 2003 Aug;35(8):1381-1395. [doi: 10.1249/01.MSS.0000078924.61453.FB] [Medline: 12900694]

45. Ström M, Uckelstam C, Andersson G, Hassmén P, Umefjord G, Carlbring P. Internet-delivered therapist-guided physical activity for mild to moderate depression: a randomized controlled trial. PeerJ 2013; 1:e178 [FREE Full text] [doi: 10.7717/peerj.178] [Medline: 24109561]

46. Joseph RP, Durant NH, Benitez TJ, Pekmezi DW. Internet-Based Physical Activity Interventions. Am J Lifestyle Med 2014 Dec;8(1):42-68 [FREE Full text] [doi: 10.1177/1559827613498059] [Medline: 25045343]

47. Borrelli B. The Assessment, Monitoring, and Enhancement of Treatment Fidelity In Public Health Clinical Trials. J Public Health Dent 2011;71(s1):S52-S63 [FREE Full text] [doi: 10.1111/j.1752-7325.2011.00233.x] [Medline: 21499543]

48. Brawley LR, Arbour-Nicitopoulos KP, Martin GKA. Developing physical activity interventions for adults with spinal cord injury. Part 3: a pilot feasibility study of an intervention to increase self-managed physical activity. Rehabil Psychol 2013 Aug;58(3):316-321. [doi: 10.1037/a0032814] [Medline: 23978087]

49. Hardeman W, Michie S, Fanshawe T, Prevost AT, Mcloughlin K, Kinmonth AL. Fidelity of delivery of a physical activity intervention: predictors and consequences. Psychol Health 2008;23(1):11-24. [doi: 10.1080/08870440701615948] [Medline: 25159904]

50. Hankonen N, Sutton S, Prevost AT, Simmons RK, Griffin SJ, Kinmonth AL, et al. Which behavior change techniques are associated with changes in physical activity, diet and body mass index in people with recently diagnosed diabetes? Ann Behav Med 2015 Feb;49(1):7-17 [FREE Full text] [doi: 10.1007/s12160-014-9624-9] [Medline: 24806469]

51. Williams C, Wilson P, Morrison J, McMahon A, Walker A, Andrew W, et al. Guided self-help cognitive behavioural therapy for depression in primary care: a randomised controlled trial. PLoS One 2013;8(1):e52735 [FREE Full text] [doi: 10.1371/journal.pone.0052735] [Medline: 23326352]

52. Whitehead AL, Julious SA, Cooper CL, Campbell MJ. Estimating the sample size for a pilot randomised trial to minimise the overall trial sample size for the external pilot and main trial for a continuous outcome variable. Stat Methods Med Res 2016 Jun;25(3):1057-1073 [FREE Full text] [doi: 10.1177/0962280215588241] [Medline: 26092476]

53. Edwards P. Questionnaires in clinical trials: guidelines for optimal design and administration. Trials 2010;11:2 [FREE Full text] [doi: 10.1186/1745-6215-11-2] [Medline: 20064225]

54. Mailey EL, Wójcicki TR, Motl RW, Hu L, Strauser DR, Collins KD, et al. Internet-delivered physical activity intervention for college students with mental health disorders: a randomized pilot trial. Psychol Health Med 2010 Dec;15(6):646-659. [doi: 10.1080/13548506.2010.498894] [Medline: 21154018]

55. Cuijpers P, de Wit L, Taylor A. The effects of psychological treatments for adult depression on physical activity: A systematic review. Mental Health and Physical Activity 2014 Mar;7(1):6-8. [doi: 10.1016/j.mhpa.2014.01.002]

56. Helgadóttir B, Owen N, Dunstan DW, Ekblom Ö, Hallgren M, Forsell Y. Changes in physical activity and sedentary behavior associated with an exercise intervention in depressed adults. Psychology of Sport and Exercise 2017 May;30:10-18. [doi: 10.1016/j.psychsport.2017.01.006]

57. Helgadóttir B, Forsell Y, Ekblom Ö. Physical activity patterns of people affected by depressive and anxiety disorders as measured by accelerometers: a cross-sectional study. PLoS One 2015;10(1):e0115894 [FREE Full text] [doi: 10.1371/journal.pone.0115894] [Medline: 25585123]

58. GOV.UK. Physical activity guidelines for Adults (19-64 years) URL: https://www.gov.uk/government/publications/ uk-physical-activity-guidelines [accessed 2018-04-25] [WebCite Cache ID 6ywMz0wvb]

59. Harvey SB, Øverland S, Hatch SL, Wessely S, Mykletun A, Hotopf M. Exercise and the Prevention of Depression: Results of the HUNT Cohort Study. Am J Psychiatry 2018 Dec 01;175(1):28-36. [doi: 10.1176/appi.ajp.2017.16111223] [Medline: $\underline{28969440]}$

60. Ainsworth B, Steele M, Stuart B, Joseph J, Miller S, Morrison L, et al. Using an Analysis of Behavior Change to Inform Effective Digital Intervention Design: How Did the PRIMIT Website Change Hand Hygiene Behavior Across 8993 Users? Ann Behav Med 2017 Jun;51(3):423-431 [FREE Full text] [doi: 10.1007/s12160-016-9866-9] [Medline: 27909944]

61. Yardley L, Spring BJ, Riper H, Morrison LG, Crane DH, Curtis K, et al. Understanding and Promoting Effective Engagement With Digital Behavior Change Interventions. Am J Prev Med 2016 Nov;51(5):833-842. [doi: 10.1016/j.amepre.2016.06.015] [Medline: 27745683]

62. Chalder M, Wiles NJ, Campbell J, Hollinghurst SP, Searle A, Haase AM, et al. A pragmatic randomised controlled trial to evaluate the cost-effectiveness of a physical activity intervention as a treatment for depression: the treating depression with 
physical activity (TREAD) trial. Health Technol Assess 2012;16(10):1-164, iii [FREE Full text] [doi: 10.3310/hta16100] [Medline: 22398106]

63. Vickers KS, Patten CA, Lewis BA, Clark MM, Ussher M, Ebbert JO, et al. Feasibility of an exercise counseling intervention for depressed women smokers. Nicotine Tob Res 2009 Aug;11(8):985-995 [FREE Full text] [doi: 10.1093/ntr/ntp101] [Medline: 19541948 ]

64. Richards DA, Ekers D, McMillan D, Taylor RS, Byford S, Warren FC, et al. Cost and Outcome of Behavioural Activation versus Cognitive Behavioural Therapy for Depression (COBRA): a randomised, controlled, non-inferiority trial. Lancet 2016 Aug 27;388(10047):871-880 [FREE Full text] [doi: 10.1016/S0140-6736(16)31140-0] [Medline: 27461440]

65. Wiles N, Thomas L, Abel A, Barnes M, Carroll F, Ridgway N, et al. Clinical effectiveness and cost-effectiveness of cognitive behavioural therapy as an adjunct to pharmacotherapy for treatment-resistant depression in primary care: the CoBalT randomised controlled trial. Health Technol Assess 2014 May;18(31):1-167, vii. [doi: 10.3310/hta18310] [Medline: 24824481]

66. Memon A, Taylor K, Mohebati LM, Sundin J, Cooper M, Scanlon T, et al. Perceived barriers to accessing mental health services among black and minority ethnic (BME) communities: a qualitative study in Southeast England. BMJ Open 2016 Dec 16;6(11):e012337 [FREE Full text] [doi: 10.1136/bmjopen-2016-012337] [Medline: 27852712]

67. Suresh K. An overview of randomization techniques: An unbiased assessment of outcome in clinical research. J Hum Reprod Sci 2011 Jan;4(1):8-11 [FREE Full text] [doi: 10.4103/0974-1208.82352] [Medline: 21772732]

68. Razykov I, Ziegelstein RC, Whooley MA, Thombs BD. The PHQ-9 versus the PHQ-8--is item 9 useful for assessing suicide risk in coronary artery disease patients? Data from the Heart and Soul Study. J Psychosom Res 2012 Sep;73(3):163-168. [doi: 10.1016/j.jpsychores.2012.06.001] [Medline: 22850254]

69. Craig P, Dieppe P, Macintyre S, Michie S, Nazareth I, Petticrew M, et al. Developing and evaluating complex interventions: the new Medical Research Council guidance. BMJ 2008;337:a1655 [FREE Full text] [Medline: 18824488]

\author{
Abbreviations \\ BA: behavioral activation \\ BCTs: behavior change techniques \\ CeHReS: Centre for eHealth Research and Disease Management \\ CSQ-SF: Client Satisfaction Questionnaire-Short Form \\ GAD-7: General Anxiety Disorder scale \\ IPAQ-SF: International PA Questionnaire-Short Form \\ MVPA: moderate-to-vigorous intensity physical activity \\ PA: physical activity \\ PHQ-8: Patient Health Questionnaire 8 \\ PIS: participant information sheet \\ RCT: randomized controlled trial \\ SMD: standardized mean difference \\ TIDieR: Template for Intervention Description and Replication
}

Edited by R Calvo, M Czerwinski, J Torous, G Wadley; submitted 13.02.18; peer-reviewed by M Stuckey, E Dove, K Ng; comments
to author 11.04.18; revised version received 08.05.18; accepted 10.05.18; published 16.07.18
Please cite as:
Lambert JD, Greaves CJ, Farrand P, Price L, Haase AM, Taylor AH
Web-Based Intervention Using Behavioral Activation and Physical Activity for Adults With Depression (The eMotion Study): Pilot
Randomized Controlled Trial
J Med Internet Res $2018 ; 20(7):$ e10112
URL: $\underline{\text { http://www.jmir.org/2018/7/e10112/ }}$
doi: $10.2196 / 10112$
PMID: $\underline{30012547}$

CJeffrey D Lambert, Colin J Greaves, Paul Farrand, Lisa Price, Anne M Haase, Adrian H Taylor. Originally published in the Journal of Medical Internet Research (http://www.jmir.org), 16.07.2018. This is an open-access article distributed under the terms of the Creative Commons Attribution License (https://creativecommons.org/licenses/by/4.0/), which permits unrestricted use, distribution, and reproduction in any medium, provided the original work, first published in the Journal of Medical Internet Research, is properly cited. The complete bibliographic information, a link to the original publication on http://www.jmir.org/, as well as this copyright and license information must be included. 